\title{
Preparation and Characterization of Hybrid Polymer-Inorganic Solar Cells Sub-Module
}

\author{
Erlyta Septa Rosa ${ }^{a}$, Shobih ${ }^{\text {a }}$, Fauzie Rachman P. ${ }^{\text {, }}$, and Abdul Hafid Ismail ${ }^{\text {b }}$ \\ ${ }^{a}$ Research Center for Electronics and Telecommunication \\ Indonesian Institute of Sciences (PPET - LIPI) \\ Kampus LIPI GD. $20 \mathrm{Jl}$. Sangkuriang \\ Bandung - Indonesia \\ Email : erlytasr@gmail.com \\ ${ }^{b}$ Chemical Engineering Department \\ Politeknik Negeri Bandung \\ Jl. Gegerkalong Hilir, Ds. Ciwaruga, \\ Bandung - Indonesia
}

\begin{abstract}
In this study, we propose a method for preparation of hybrid polymer solar cell sub-module, which is achieved by internally series-interconnection of 3 (three) single hybrid polymer solar cells based on MDMO-PPV and $\mathrm{ZnO}$ blend on a flexible substrate. The structure of the device was ITO/PEDOT-PSS/ZnO:MDMO-PPV/Ag. The resulting sub-module has electrical characteristics of open circuit voltage $\left(\mathrm{V}_{\mathrm{oc}}\right)$ of $1.22 \mathrm{~V}$, short circuit current $\left(\mathrm{J}_{\mathrm{sc}}\right)$ of $0.11 \mathrm{~mA} / \mathrm{cm}^{2}$, maximum power $\left(\mathrm{P}_{\mathrm{m}}\right)$ of $0.01 \mathrm{~W}$, and power conversion efficiency (PCE) of $0.08 \%$.
\end{abstract}

Keywords: hybrid, polymer solar cells, sub-modules, series-interconnection, MDMO-PPV, ZnO.

\section{Introduction}

Solar cells have been studied extensively in recent years as clean, sustainable, and renewable-energy sources due to the increasing global energy crisis ${ }^{1}$. Solar cells are usually made from silicon, the same material used for transistors and integrated circuits ${ }^{2}$. Silicon solar cells have been known for more than a half century because of have mature technologies of fabrication, allowing these devices to possess relatively stable and superior properties. Power conversion efficiencies in silicon cells are as high as $20 \%$, and their service life is more than 25 years. Unfortunately, expensive cost of manufacturing processes reduces the advantages of these inorganic solar cells, resulting in difficulties in popularization of solar cell systems ${ }^{3}$. A broad range of solar cell technologies is currently being developed, including dye-sensitized, nanocrystalline photoelectron chemical solar cells, polymer/fullerene bulk heterojunctions, small-molecule thin films and organic/inorganic hybrid solar cells. Hybrid solar cells are a mixture of nanostructures of both organic and inorganic materials ${ }^{2}$.

Hybrid polymer-inorganic solar cells offer the opportunity to combine the beneficial properties of the two materials in charge generation and transport with easy and cheap processing in large areas. Various strategies, for creating hybrid polymer solar cells have been explored in recent years. Many of these methods aim at creating an intimately mixed bulk-heterojunction microstructure of the two materials on a nanometer scale, ensuring efficient charge generation at the interface and effective percolating pathways for photogenerated electrons and holes to the electrodes ${ }^{4}$.

In recent years, researchers have also attempted to enlarge these solar cells for practical use ${ }^{5}$. The fabricated cells should be externally interconnected in series or parallel to be used in more large-scale modules, as this monolithic approach is well established in crystalline silicon solar module manufacturing. Another approach is to internally connect arrays of parallel single cells in series to enlarge a single module. This technique is widely used in thin film solar cells to 
boost the voltage of the module. Voltage boosting is favored over current boosting because voltage boosting produces lower ohmic losses in low-conductivity substrates ${ }^{5}$.

In this study, we propose a method for preparation of hybrid polymer solar cell sub-module, which is achieved by internally series-interconnection of 3 (three) single hybrid polymer solar cells based on MDMO-PPV and $\mathrm{ZnO}$ blend. The structure of the cells was PET/ITO/PEDOT-PSS/ZnO:MDMO-PPV/Ag.

\section{Hybrid Polymer-Inorganic Solar Cells}

Organic solar cells (OSCs) materials are under intensive study for potential application in low-cost and largearea solar cells. Power conversion efficiencis exceeding $3 \%$ have been reported in several device configurations. Although all-organic systems such as polymer/fullerene blend are receiving high interest, these systems suffer from poor photostability of the two organic components and poor mechanical stability of the active layer through phase segregation ${ }^{6}$. One promising alternative approach is to use a nanostructured inorganic semiconductor as the electron-transport component. Electron-transporting metal oxide such as titanium dioxide $\left(\mathrm{TiO}_{2}\right)$, tin oxide $\left(\mathrm{SnO}_{2}\right)$, and zinc oxide $(\mathrm{ZnO})$ is attractive materials in this content on account of their low cost, good stability, ease of fabrication, and their potential that exists for controlling their film morphology on the nanoscale (6).

Hybrid polymer solar cells (HSCs) use a combination of a conjugated polymer and an inorganic semiconductor to convert sunlight into charges. The use of two materials with complementary $\mathrm{p}$ and $\mathrm{n}$ type electronic property is crucial in the operation of any (hybrid) polymer solar cell because photoexcitation of a conjugated polymer provides a bound electron-hole pair or exciton rather than free charges. This exciton can be dissociated efficiently at the interface with a second material via a hole or electron transfer to produce the free charges that generate the photovoltaic effect (7). Fig. 1 gives the schematic illustration of the energy level alignment and the photo current generation mechanism in HSCs (8).

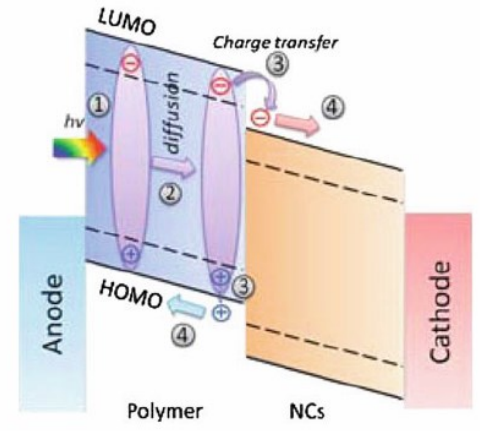

Fig.1. Schematic illustration of the energy level's alignment and photo current generation mechanism in hybrid solar cells (8).

Upon illumination, the photo current is generated via the following processes ${ }^{8}$ :

- Photo absorption and exciton generation. The conjugated polymers mainly account for the light absorption in HSCs. In some cases, the inorganic nanocrystals could also absorb light, but the majority of the light absorptions are attributed to the conjugated polymers. The light harvesting efficiency (gLHE) is determined by the bandgap ( $\mathrm{Eg})$ and the absorption coefficient of the polymers. After absorbing the incident photons, electrons will be excited from the highest occupied molecular orbit (HOMO) to the lowest unoccupied molecular orbit (LUMO). Due to the low dielectric constant of the polymers, the electrons in LUMO and the holes in HOMO are not free charges but excitons with strong Coulomb interaction. The exciton binding energy $(\mathrm{Eb})$ is typically $0.2-0.5 \mathrm{eV}$. Therefore, the exciton generation efficiency $\left(g_{g}\right)$, which is regarded as the possibility of generating one exciton by one photon, is critical in the device performance. In addition, the excitons have a good chance to recombine.

- Exciton diffusion. Before separating into free charges, the excitons have to diffuse to the D/A interfaces. The exciton diffusion efficiency (gdiff) depends on how much the excitons could successfully diffuse to the D/A interface before recombination takes place. It noted that the exciton diffusion length is $4-20 \mathrm{~nm}$ for the most conjugated polymers, the D/A domains in HSCs should also be in this range for high exciton diffusion efficiency.

- Exciton dissociation. Once reaching the D/A interface, excitons could be dissociated into free electrons and holes if the energy offsets between 
the LUMO of the polymer and the conduction band (CB) of the inorganic nanocrystals overcomes the binding energy of the excitons; therefore, the relative positions of the LUMO of the Donors and the $\mathrm{CB}$ level of the inorganic acceptors determine the exciton dissociation efficiency (gd).

- Charge transfer and collection. After the exciton dissociation, the free electrons and holes need to transfer through the inorganic nanocrystals and conjugated polymers until they are collected at the electrodes. The charge transfers efficiency (gtr) is related to the intrinsic properties of the materials, e.g., the carrier mobility, the crystallinity and the purity, and so on. Besides, continuous pathways are also needed for efficient charge transfer. While the charge collection efficiency (gcc) mainly depends on the energy level alignments of the active layer and the electrodes as well as the contact between them.

\section{Experimental Method}

Hybrid polymer solar cell sub-module was prepared by internally series-interconnection of 3 (three) single cells based on MDMO-PPV and $\mathrm{ZnO}$ blend. The structure of the cells was PET/ITO/PEDOT-PSS/ZnO:MDMOPPV/Ag. Fig. 2 shows the design structure and pattern for the fabrication of series interconnected hybrid polymer solar cell sub-module based on MDMOPPV:ZnO.

The devices were fabricated on cleaned indium tin oxide (ITO) patterned Polyethylene Terephthalate (PET) substrates (sheet resistivity $60 \Omega / \square$ ). First, a layer of PEDOT:PSS was deposited on top of the ITO by spin coating and annealing at $120{ }^{\circ} \mathrm{C}$ for $60 \mathrm{~min}$ in vaccum oven. Then the active layer was spun from a $\mathrm{ZnO}$ nanoparticle/MDMO-PPV (7:3 ratio by mass) solution using chlorobenzene:propanol (5 vol.\%) as the solvent. After spin coating, $30 \mathrm{~nm}$ of silver $(\mathrm{Ag})$ is deposited onto the active layer by thermal evaporation.

To protect the cells from environment, a PET sheet was employed at the back of the device by a lamination process. The sealant was placed between the device and PET and cured in a vacuum oven at $100{ }^{\circ} \mathrm{C}$ for 10 minutes.

All the current density-voltage $(\mathrm{J}-\mathrm{V})$ characteristics of the cells and module were measured in ambient conditions using a computer-controlled National Instrument source measure unit. Active area of each cell is $2.60 \mathrm{~cm}^{2}$, so that the active area of sub-module into $(3$ $x 2.60) \mathrm{cm}^{2}$. The device performance was measured with $500 \mathrm{~W} / \mathrm{cm}^{2}$ AM $1.5 \mathrm{G}$ illumination using a commercial solar simulator (Oriel) equipped with long pass UV filter which inserted between light source and device.

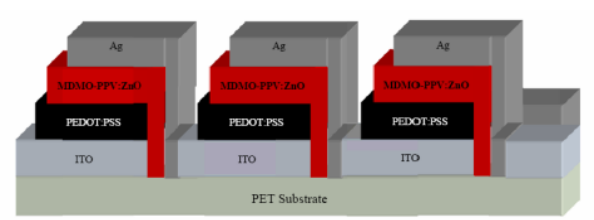

(a)

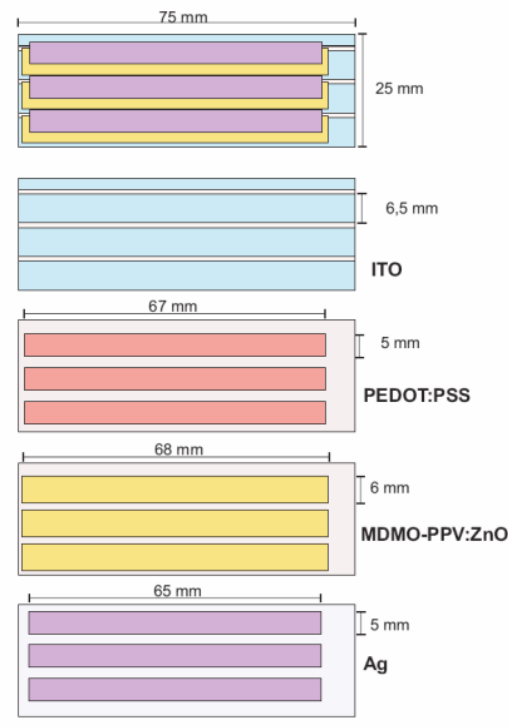

(b)

Fig. 2. Design structure (a) and pattern (b) for the fabrication of series interconnected hybrid polymer solar cell sub-module based on MDMO-PPV:ZnO.

\section{Results and Discussion}

Fig. 3 shows a picture of hybrid polymer solar cell submodule which is achieved by internally seriesinterconnection of 3 (three) single hybrid polymer solar cells based on MDMO-PPV and $\mathrm{ZnO}$ blend on a flexible substrate. The I-V and electrical characteristics under $500 \mathrm{~W} / \mathrm{cm}^{2} \mathrm{AM} 1.5 \mathrm{G}$ illuminations of each cell and sub-module were presented in fig. 4 and Table 1. 


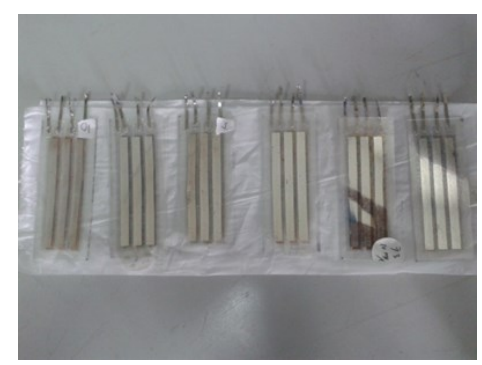

Fig. 3. Picture of hybrid polymer solar cell sub-module consisting of three single cells.

A highly interesting phenomenon in polymer solar cell is the observation of unusual high open-circuit voltage $\left(\mathrm{V}_{\mathrm{oc}}\right)^{9-10}$. The results obtained from fig. 4 and table 1 show that the cell-1 and cell-3 has similar $\mathrm{V}_{\mathrm{oc}}$, which is about $0.65 \mathrm{~V}$, whereas cell-2 has higher $\mathrm{V}_{\text {oc }}$, namely $0.77 \mathrm{~V}$. The calculated open-circuit voltage submodule should have a combination of all three cells, which is about $2.07 \mathrm{~V}$. However, Voc obtained in this research is lower than calculated, about $1.22 \mathrm{~V}$.

The short-circuit photo-current density $\left(\mathrm{J}_{\mathrm{sc}}\right)$ for cell-1, cell-2, and cell-3 are $0.0593 \mathrm{~A} / \mathrm{cm}^{2}, 0.0696 \mathrm{~A} / \mathrm{cm}^{2}$, and $0.0627 \mathrm{~A} / \mathrm{cm}^{2}$, respectively. All of cells have similar $\mathrm{J}_{\mathrm{sc}}$, while the $\mathrm{I}_{\mathrm{sc}}$ of the module is higher than the cells, which is $0.1121 \mathrm{~A} / \mathrm{cm}^{2}$.

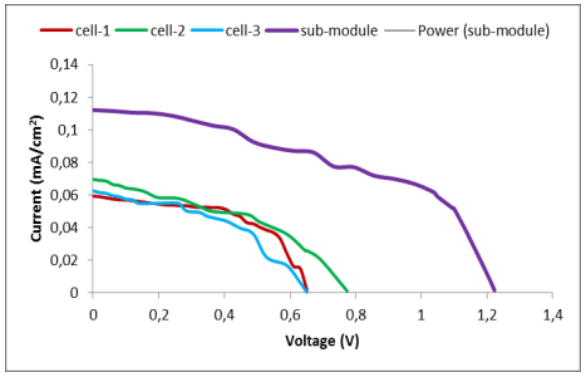

Fig. 4. I-V characteristics of cell-1, cell-2, cell-3 and submodule of hybrid polymer solar cells based on MDMO-PPV and $\mathrm{ZnO}$ blend on a flexible substrate.

Table1. Electrical characteristics of cell 1, cell 2, cell 3 and sub-module hybrid polymer solar cells based on MDMO-PPV and $\mathrm{ZnO}$ blend on a flexible substrate.

\begin{tabular}{ll}
\hline $\begin{array}{l}\text { Electrical } \\
\text { Characteristics }\end{array}$ & Cell-1 Cell-2 Cell-3 Sub-modul \\
\hline $\mathrm{V}_{\mathrm{oc}}(\mathrm{V})$ & $0,651 \leq 0.774(0,65141,2227$ \\
$\mathrm{J}_{\mathrm{sc}}\left(\mathrm{A} / \mathrm{cm}^{2}\right)$ & $0,059 \geqq 0,06960,062 ; 0,1121$ \\
\hline
\end{tabular}

\begin{tabular}{ll}
\hline $\mathrm{P}_{\max }(\mathrm{W})$ & 0.00710 .00540 .00410 .0078 \\
$\mathrm{FF}$ & $0.492(0.33800 .32020 .3818$ \\
$\mathrm{PCE}(\%)$ & $0.001<0.00110 .000 £ 0.0763$ \\
\hline
\end{tabular}

The overall power conversion efficiency (PCE) is determined as the fraction of incident power, which is converted to electricity, and defined from the ratio of energy output from the solar cell to input energy from the sun. It is calculated from the short-circuit current, the open-circuit voltage, the fill factor, and the intensity of the incident light $\left(\mathrm{P}_{i n}\right)$ using the formula ${ }^{11}$ :

$$
\begin{aligned}
& P C E=\frac{V_{m} I_{m}}{P_{i n}}=\frac{F F V_{O C} I_{S C}}{\phi A} \times 100 \% \\
& F F=\frac{V_{m} I_{m}}{V_{o c} I_{s c}}
\end{aligned}
$$

Where $V_{m}, I_{m}, F F, \Phi$ and $A$ were the maximum voltage, the maximum current, the fill factor, the light intensity and the coverage area, respectively.

The PCE of the cell-1, cell-2, and cell-3 are 0.0014 $\%, 0.0011 \%$, and $0.0008 \%$, respectively. PCE of $1.23 \%$ was observed when the cells were interconnected into a sub-module where the PCE reached $0.0763 \%$. These results are lower than the value reported by Beek et al. (7); this may be a result of low $I_{s c}$. The low in $I_{s c}$ values indicates low electron collection efficiencies which in turn indicate slow electron diffusion rates, and thereby decrease the photo conversion efficiency.

\section{Conclusion}

We have proposed method for preparation of hybrid polymer solar cell sub-modules, which is achieved by internally series-interconnection of 3 (three) single hybrid polymer solar cells based on MDMO-PPV and $\mathrm{ZnO}$ blend on a flexible substrate.

The resulting sub-module has electrical characteristics of open circuit voltage of $1.22 \mathrm{~V}$, short circuit current of $0.11 \mathrm{~mA} / \mathrm{cm}^{2}$, maximum power of $0.008 \mathrm{~W}$, and power conversion efficiency of $0.08 \%$.

\section{Acknowledgement}

This work was supported by Research Center for Electronics and Telecommunication Indonesian Institute of Sciences (PPET LIPI) through DIPA Program 2014. 


\section{References}

1. S. Shao, F. Liu, Z. Xie, and L. Wang, High-Efficiency Hybrid Polymer Solar Cells with Inorganic P- and NType Semiconductor Nanocrystals to Collect Photogenerated Charges, J. Phys. Chem. C. 114 (2010) 9161-9166.

2. J. Chandrasekaran, D. Nithyaprakash, K.B. Ajjan, S. Maruthamuthu, D. Manoharan, S. Kumar, Hybrid solar cell based on blending of organic and inorganic materials-An overview, Renew. Sustain. En. Rev. 15 (2011) 1228-1238.

3. P. A. Troshin, R. N. Lyubovskaya, V. F. Razumov, Organic Solar Cells: Structure, Materials, Critical Characteristics, and Outlook", Nanotech. Russia, 3 (5-6) (2008) 242-271.

4. W.J.E. Beek and R.A.J. Janssen, Hybrid PolymerInorganic Solar Cells, in Hybrid Nanocomposites for Nanotechnology, (Springer Science + Business Media, 2009), pp. 324.

5. J. Lee, H. Back, J. Kong, D.W. Park, K. Lee, New series connection method for bulk-heterojunction polymer solar cell modules, Sol. En. Mat. \& Sol. Cells. 98 (2012) 208211.

6. P. Ravirajan, S.A. Haque, J.R. Durran, D.D.C. Bradley, and J. Nelson, The Effect of Polymer Optoelectronic Properties on the performance of Multilayer Hybrid Polymer/TiO 2 Solar Cells, Adv. Funct. Mater. 15 (4) (2005) 609-618.

7. W.J.E. Beek, M.M. Wienk, and R.A.J. Janssen, Hybrid polymer solar cells based on zinc oxide, J. Mater. Chem. 15 (2005) 2985-2988.

8. Q. Tai and F. Yan, Hybrid Solar Cells with Polymer and Inorganic Nanocrystals in Organic Solar Cells (W. C. H. Choy ed.), (Green Energy and Technology SpringerVerlag, London, 2013) pp. 244-245.

9. C.J. Brabec, Organic Photovoltaics: Technology and Market", Sol. En. Mat. \& Sol. Cells, 83 (2004) 273-292.

10. S. E. Shaheen, C. J. Brabec, and N. S. Sariciftci, $2.5 \%$ Efficient Organic Plastic Solar Cells, Appl. Phys. Lett., 78(6) (2001) 841-843.

11. M. Wright and A. Uddin, Organic-inorganic hybrid solar cells: A comparative review, Sol. En. Mat. \& Sol. Cells, 707 (2012) 87-111. 